\title{
Elicitation and generation of a script for the acquisition of household appliances within a consumer decision-making context
}

\author{
Alet C Erasmus, Elizabeth Boshoff and GG Rousseau
}

\begin{abstract}
OPSOMMING
Hoewel geskrifte as ' $n$ geldige konstruk in verskeie dissiplines soos kognitiewe sielkunde erken en gebruik word, is min gedoen om die potensiaal van aankoopgeskrifte verder te ontgin sedert die eerste inisiatiewe in die 1980's. Die doel van hierdie studie was om 'n teks vir die aankoop van groot huishoudelike toerusting binne verbruikersbesluitnemingsverband te ontwikkel as ' $n$ meer realistiese voorstelling van die aankoopproses as wat deur tradisionele verbruikersbesluitnemingsmodelle voorgehou word.
\end{abstract}

Vorige navorsing op hierdie gebied is in aanmerking geneem (Erasmus et al, 2002b) om data-insameling te struktureer en maksimaal te benut vir die generering van ' $n$ geskrif wat aan die basiese eienskappe en strukturele vereistes van geskrifte sou voldoen. ' $n$ Emiese, ideografiese navorsingsbenadering is gevolg (Denzin \& Lincoln, 2000:10,158). Veelvoudige data-insamelingstegnieke is gebruik om sydigheid te voorkom. Minder gestruktureerde tegnieke is gebruik en selektief gekombineer (Erasmus et al, 2002a). Data is direk na insameling verwerk sodat die resultate in opeenvolgende data insamelingsessies in aanmerking geneem kon word om leemtes uit te skakel.

Die keuse, kombinasie en volgorde van implementering van die onderskeie data-insamelingstegnieke het meegewerk om die relevante norme te identifiseer en dit moontlik gemaak om 'n teks wat aan die basiese eienskappe en strukturele eienskappe wat vir tekse voorgehou word, saam te stel. Die spesifieke volgorde van tegnieke kan vir soortgelyke studies aanbeveel word: die geskrewe tegniek was veral suksesvol om al die aktiwiteite (elemente) te identifiseer, terwyl daaropvolgende tegnieke bygedra het om elemente uit te brei, om betroubaarheid en geldigheid te verseker en om visuele stimuli vir die diskrimineringstegniek saam te stel.

\section{- Dr AC Erasmus \\ - Prof E Boshoff}

Department of Consumer Science,

University of Pretoria

\section{- Prof GG Rousseau}

Department of Industrial Psychology

University of Port Elizabeth

\section{INTRODUCTION}

Despite the overwhelming impact of technology on household appliances in recent times, an understanding of consumers' choice processes in acquiring appliances is still fragmented and under-researched (Venkatesh, 1985). When judged within the framework of a traditional consumer decision-making model, decision-making for purchasing major household appliances is typically categorized as a complex, highrisk consumer decision. While it seems extensive and rather elaborate one wonders whether consumers really undertake such extensive deliberation before purchasing household appliances.

Several objections against the use of traditional consumer decision-making models without careful premeditation of the context and purpose within which they are used, have been published in recent years (Erasmus et al, 2001). In response to initial objections, Schurr (1986) inter alia suggested purchasing scripts as alternative frameworks of consumer decision-making, accentuating specific advantages of script theory. In contrast to consumer decisionmaking models, scripts inter alia identify the principle actions, the people (actors) and the objects involved in a recurring situation/event (Calder \& Schurr, 1981 in Speck et al, 1988; Schurr, 1986); a script is further considered to be a schematic portrayal of a consumer's mental representation of a specific event and contains a sequence of actions from the point of view of the consumer (Abelson, 1981). Scripts consequently have the potential to offer valuable insights into consumer behaviour and to provide professionals in the field of consumer science with valuable guidelines on how to facilitate consumer behaviour (Lai, 1994; Taylor et al, 1991; Bozinoff, 1982).

An attempt to elicit and organize a script that could serve as a realistic portrayal of the process of purchasing major household appliances seems to coincide with recommendations for research in the field of consumer behaviour. The script concept is generally accepted to be a valid construct with wide application (Taylor et al, 1991) and is used in areas such as cognitive, social, developmental and clinical psychology as well as cognitive anthropology (Rummelhart, 1980 and Abelson, 1976 in Leigh \& Rethans, 1983; Barlett, 1932, Bransford \& Franks, 1971, Mandler, 1979, Minsky, 1975, Rummelhart \& Ortony, 1977, Schank \& Abelson, 1977 in John \& Whitney, 1982). Unfortunately, since the introduction of scripts within the domain of consumer behaviour and since the first script- 
elicitation studies (Whitney \& John's shopping script, 1983 and Stoltman \& co workers' examination of shopping scripts in 1989), little has been done to implement it in consumer behaviour studies or to explore its potential to reflect the consumer decision-making process for specific purchasing events.

In reaction to concerns regarding the use of traditional consumer decision-making models to reflect consumer decision-making in general (Erasmus et al, 2001), the following research problem was formulated:

Can a script that conforms to the properties and structural characteristics of a script according to basic script theory be elicited and organized within the consumer behaviour context to portray the acquisition of major household appliances?

\section{RESEARCH DESIGN}

\section{Research objective and sub-objectives}

\section{The research objective was formulated as follows:}

To elicit and organize a script for the acquisition of major household appliances within the consumer decision-making context that coincides with the basic properties and structural characteristics of a theoretical script.

\section{Sub objectives were:}

To elicit the relevant script norms for the organization of a script for the acquisition of major household appliances, i.e. to stimulate experienced consumers to spontaneously expose/identify the relevant:

- person schemata: everybody involved during the decision-making process

- role schemata: the contribution of participants during the decision-making process, i.e. so-called influencers, decision-makers, et cetera

- object schemata: the various objects involved in the decision-making process, e.g. information sources, retail outlets

- decision-making schemata: the actions taken/implemented during the decision-making process.

To generate a script that coincides with the basic properties and structural characteristics of a script within basic script theory by integrating and ordering the relevant script norms and actions indicated as typical of the event (acquisition of major household appliances).

\section{Conceptual framework and definition of concepts}

Following an ideographic approach, no assumptions were made concerning the various elements of decision-making to be expected in a script, the concepts pertaining to the phenomena relevant to the study or their inter-relationship. These were to be elicited during the research process by allowing participants to spontaneously share their cognitive representations of the event irrespective of any resemblance to traditional consumer decision-making models. Broad nonspecific concepts were however identified to set the parameters for the study in accordance with the objectives of the study.

Acquisition of household appliances The acquisition of household appliances refers to the decision-making process from the point where the need to replace an appliance is acknowledged until it is installed at home. No assumptions regarding typical/traditional stages of decision-making were made. Instead, participants were asked to reconstruct a purchasing event through various elicitation techniques.

Major household appliances include cooling, cooking, baking and laundry appliances and are in the trade referred to as white goods. These are the more expensive household appliances used in kitchens and laundries and are generally considered long-term purchases due to their expected service life. For this study, washing machines were used as an example of major household appliances because washing machines seem to be the most frequently purchased appliances in a household and are seldom purchased without prior deliberation (Cox et al, 1983). Script theory postulates that a script for one event (the acquisition of a washing machine) will eventually be made applicable to a related event (similar purchases, for example stoves, tumble-driers). A script for the acquisition of washing machines can thus also be interpreted as a script for major household appliances.

Script A script for the acquisition of major household appliances can be referred to as a written portrayal of the purchasing event (for household appliances) as reconstructed from the view of experienced consumers. Theoretically, scripts are also known as event schemata. Script content is stored in long-term memory as hypothetical knowledge structures. These schemata are developed through experience and over learning and are retrieved to direct behaviour whenever consumers are exposed to/confronted with the same or similar situations (Speck et al, 1988; Bozinoff \& Roth, 1983; Whitney \& John, 1983).

Script norms A script has to coincide with certain characteristics and properties as specified in basic script theory (Abelson, 1981). The so-called script norms that characterize scripts in terms of content and structure are the characters (people), their respective roles, the props/objects and actions that are present in the script in the form of person schemata, role schemata, object schemata and action/decision-making schemata respectively. Their integration and ordering eventually reflects the specific event.

Schemata Schemata are described as stored frameworks (cognitive structures) of knowledge about specific objects or topics in semantic memory (Brown, 1992) and can be defined as abridged, generalized, 
corrigible organizations of experience that serve as frames of reference for action and perception of similar experiences (Weick in Schurr, 1986). A schema is linked to a specific experience and contains general/generic knowledge about that domain. When one is exposed to any object or situation, a schema is retrieved from long-term memory into working memory to serve as a frame of reference so that one is able to interpret, accept and understand the object/situation (Brown, 1992; Hoy, 1991).

- Person schemata refer to trait-based impressions of specific people who participate in an event including their skills, competencies, and values. A person schema is not situation specific (e.g. husband).

- Role (relational) schemata specify the contribution of various individuals/actors throughout the decision-making process, e.g. as influencer or decision-maker. A role schema is situation specific and relational because it defines the probable relations between people and objects in the event and their respective roles.

- Object schemata could, within the context of this study, refer to any object used/ involved in the event (e.g. information sources). Object schemata are not situation specific.

- Decision-making schemata specify all the activities that form part of the event (e.g. information seeking).

In a script for the acquisition of major household appliances one or more of person-, object and role schema/ta will always be integrated with a decisionmaking schema to represent an action/element. All the actions/elements contained in a script are organized/divided into a number of coherent scenes that are sequentially and hierarchically ordered to represent the event schema/script.

\section{PROCEDURE}

\section{Theoretical approach}

A script-elicitation study is explorative in nature. The research kept to the voluntaristic assumption that consumers are active agents who interact with their environments and consequently gain experience, generate knowledge, beliefs and intentions that affect and direct subsequent consumer behaviour (Hudson \& Murray, 1986). Experience is thus considered an important prerequisite for participation in a script study.

An emic (seeking to expose cognitive frameworks/schemata that consumers use: an insider view), ideographic approach of enquiry was used (Denzin \& Lincoln, 2000:10, 158). Ideograhic assumptions limit the focus to particular events/actions rather than to generalize the findings to all purchasing events (such as clothing or housing purchases) (Denzin \& Lincoln, 2000:9; Hudson \& Murray, 1986). An ideographic approach is characterized by a smaller sample and refers to the rigorous analysis of a specific decision- making event through multiple data-collection techniques to formulate interpretive statements pertaining to that specific decision-making event (a specific appliance) or to the class of phenomena represented by the event (major household appliances) (Denzin in Corsini, 1994:205). The specific research techniques that were chosen to construct an event from the point of view of the consumer are typical of the post positivist paradigm, namely projective techniques, interviews and focus group discussions (Denzin \& Lincoln, 2000:9, 10; Hudson \& Murray, 1986). The implementation of multiple techniques facilitated triangulation.

\section{Sample framework}

A prerequisite for inclusion in the script-elicitation study for household appliances was experience in taking or sharing responsibility of purchasing major household appliances for a household over a period of at least five years (Menon \& Johar, 1993).

Men and women, irrespective of marital status, between the ages of 30 and 60 years who were responsible or co-responsible for their own households were selected to exclude discriminatory issues of gender and marital status and to allow for a more egalitarian approach where husbands and wives share decision tasks (Mano \& Davis, 1990; Aldershoff, 1985; Buss \& Schaninger, 1983). Middle and higher socio economic levels were targeted to ascertain experience of the purchase situation (Du Plessis \& Rousseau, 1999:54-62; Aldershoff, 1985).

The approximate value of a residence - whether rented or owned - served as indication of socio economic status. Only participants whose housing was valued at more than R250 000 (approximate minimum monthly income per household R10 000) were included to ensure that participants had spending power and consequently relevant buying experience.

Sample Because script content is generic in nature and will contain the same basic structure for a group of experienced consumers, volunteers were recruited for participation. Potential participants were recruited for participation in a so-called consumer decision-making research project by approaching them personally or telephonically during working hours at businesses within a radius of fifteen kilometres from the University of Pretoria where the datacollection sessions were to be held. A convenience sample is defensible since the principal aim of the research is exploratory in nature and individual differences were of no theoretical interest (Bozinoff, 1982).

An effort was made to include an even distribution of individuals over different age and socio economic status levels. Rather than to inform participants of the precise aims of the study (to prevent them from preparing so-called appropriate answers), they were asked to participate in a consumer decision-making research project (Bozinoff, 1982). Upon receiving the instructions on the day of data-collection, they were allowed to withdraw if they wished. Responses were 
TABLE 1: $\quad$ PROFILE OF PARTICIPANTS FOR THE VARIOUS SCRIPT-ELICITATION STAGES

\begin{tabular}{|c|c|c|c|c|c|c|c|c|c|c|c|c|c|c|c|c|}
\hline & \multirow{2}{*}{\multicolumn{5}{|c|}{$\begin{array}{l}\text { Participants per value of homes } \\
\text { (as indication of financial status) }\end{array}$}} & \multicolumn{11}{|c|}{ Participants } \\
\hline & & & & & & \multicolumn{4}{|c|}{ Age (years) } & \multicolumn{2}{|c|}{ Language } & \multicolumn{2}{|c|}{ Gender } & \multicolumn{3}{|c|}{ Racial groups } \\
\hline & 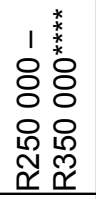 & 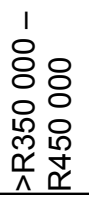 & $\begin{array}{l}1 \\
8 \\
8 \\
8\end{array}$ & $\begin{array}{l}1 \\
8 \\
8 \\
8\end{array}$ & $\begin{array}{l}* \\
x \\
8 \\
8 \\
0 \\
0 \\
0 \\
0 \\
0 \\
1 \\
1\end{array}$ & $\begin{array}{l}\text { Pे } \\
\text { ô } \\
\end{array}$ & $\begin{array}{l}9 \\
\text { o } \\
\text { o } \\
\end{array}$ & $\begin{array}{l}0 \\
0 \\
0 \\
0 \\
i n\end{array}$ & $\begin{array}{l}+ \\
8\end{array}$ & 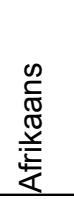 & 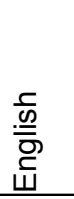 & $\frac{\infty}{\sum^{\pi}}$ & 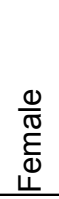 & $\stackrel{0}{\stackrel{0}{*}}$ & $\begin{array}{l}\frac{r}{0} \\
\frac{\pi}{0} \\
\end{array}$ & $\begin{array}{l}\bar{d} \\
\stackrel{\bar{\nu}}{0} \\
\text { 응 } \\
0\end{array}$ \\
\hline $\begin{array}{l}\text { STAGE } 1 \\
\mathrm{n}=57\end{array}$ & 13 & 12 & 10 & 10 & 12 & 17 & 19 & 18 & 3 & 30 & 27 & 20 & 37 & 45 & 9 & 3 \\
\hline $\begin{array}{l}\text { STAGE } 2 \\
\mathrm{n}=25\end{array}$ & 4 & 6 & 6 & 5 & 4 & 8 & 7 & 9 & 1 & 16 & 9 & 8 & 17 & 17 & 6 & 2 \\
\hline $\begin{array}{l}\text { STAGE 3* } \\
\mathrm{n}=22\end{array}$ & 4 & 6 & 4 & 5 & 3 & 7 & 7 & 7 & 1 & 15 & 7 & 7 & 15 & 15 & 5 & 2 \\
\hline $\begin{array}{l}\text { STAGE } 4^{* *} \\
\mathrm{n}=25\end{array}$ & 3 & 5 & 6 & 6 & 5 & 8 & 8 & 8 & 1 & 17 & 8 & 7 & 18 & 20 & 4 & 1 \\
\hline $\begin{array}{l}\text { STAGE } 5^{\star \star *} \\
n=18\end{array}$ & & 8 & 2 & 4 & 4 & 8 & 4 & 6 & 0 & 14 & 4 & 7 & 11 & 18 & & \\
\hline $\begin{array}{l} \\
* \\
* * \\
* * * \\
* * * * \\
* * * * *\end{array}$ & spor & $\begin{array}{l}\text { ints a } \\
\text { age } 1 \\
\text { age } 1 \\
\text { inimu }\end{array}$ & stage & 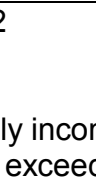 & $R$ & & & se & & & & & & & & \\
\hline
\end{tabular}

made anonymously but participants submitted personal data separately and had to indicate their willingness to participate in further stages of the study. The profiles of the samples of the five script-elicitation stages are reflected in Table 1.

\section{Data-collection site}

Data-collection stages $1,3,4$ and 5 were conducted in a laboratory setting at the University of Pretoria. This seemed convenient for participants coming from various areas and provided an intellectual atmosphere that is said to be favourable for the activation of dataladen schema (Mouton, 1996:149; Gardner \& Raj,
1983). It further allowed some control over environmental and context effects (Touliatos \& Compton, 1988:117).

\section{Data-collection and analysis}

Because schemata are stored as declarative knowledge in long-term memory and are consequently difficult to retrieve, multiple, less structured data-collection techniques were used (Huberman \& Miles, 1994:429). The researcher conducted the data-collection stages personally. A well-trained assistant (in possession of a Master's degree with Consumer Behaviour as a major) assisted with the analysis and interpretation of the

1. "Please write a detailed list of actions describing what people generally do when they buy a new washing machine to replace an old one that has broken down after ten to twelve years of service".

I am interested in the common actions of buying a new washing machine and would like to have a detailed description of the entire process of replacing a washing machine, including all individuals, objects and activities that are part of, and are involved in the process up to making the final purchase. Please describe the process in as much detail as possible - explaining the role and contribution of each and everybody. Remember $r$ to describe the type of interaction that occurs through out.

2. Start your list with: Household $r$ wants/decides to buy a new washing machine......

3. End your list with: The washing machine is delivered and installed at home.

4. Include about 20 actions/events.

5. Describe the activities/events in the order in which they occur, mentioning all the individuals, objects and activities involved through out, stipulating the extent and type of action and interaction that occur.

FIGURE1: INSTRUCTIONS FOR SCRIPT-ELICITATION THROUGH A CONCEPT DRIVEN, WRITTEN RECONSTRUCTION TECHNIQUE (STAGE 1) 
data on a continual basis and co-administered the focus groups sessions. It was hoped that the affiliation of both researcher and assistant as lecturers at the university would have a favourable influence on participants' perception of their contribution towards the outcome of the study (Mouton, 1996:149).

\section{Strategy for data-collection}

Data-collection was done in five stages to create generous opportunities to elicit a pool of generic and relevant script elements. Data driven (bottom-up) as well as conceptually driven (top-down) strategies were used: these included written and oral techniques; group and individual sessions; reconstruction as well as discrimination techniques (Erasmus et al, 2002b). Data analysis was done immediately after every data-collection stage so that results could be used to direct successive data-collection stages (Huberman \& Miles, 1994:429).

\section{Data-collection stages and techniques}

Script-elicitation techniques were implemented in the following order:

\section{Stage 1: Script-elicitation through a concept driven, written reconstruction technique}

\section{Data-collection}

Participants were requested to describe in writing and in their own words and style how people in general go about replacing a washing machine that has broken down after ten to twelve years of service (method adapted from Bower et al, 1979). To clarify decision-making/purchasing process and to capture a very specific range of statements the starting and concluding points of discussion (Start with.......End with......) were clearly indicated. The inclusion of actions, people and objects in the descriptions were also required (Figure1).

\begin{abstract}
Participants
Sixty individuals were invited to participate in groups of 15 each in four separate sessions. Fifty-eight turned up of which 57 responses could be used (Table1). Reports were written anonymously to make the situation less threatening and in language of choice (Afrikaans or English) to encourage unconstrained response.
\end{abstract}

\section{Stage 2: Script-elicitation through a concept driven, oral reconstruction technique}

\footnotetext{
Data-collection According to cognitive theory the unconscious nature of schemata in longterm memory makes it difficult to retrieve. Individual interviews provided the opportunity to use a moderately scheduled interview technique based on the results of stage 1 (written reports) but provided the opportunity to interrupt interviewees to elaborate on certain aspects to capture detail that seemed to have been under reported (Touliatos \& Compton, 1988:178). A concept driven/top down approach was followed and the same instructions to that of stage 1 were used except that responses were oral instead of written. With participants' permission, the interviews were tape-recorded for transcription.
}

Participants

Twenty-five new participants were interviewed at work during lunch-hour or after-hours in their homes. More or less the same ratio of participants from the various age and socioeconomic groups were included as for stage 1.

\section{Stage 3: Elicitation of script sub-actions and role expectations, through a data driven discrimination technique}

Data-collection The discrimination technique used (versus the association technique used in stages 1 and 2) aimed at the reconstruction of an event, to evoke contextually rich data and to minimize cognitive load (Donoghue, 2000; Stoltman et al, 1989). Responses of stages 1 and 2 were used to compile a combination of visual stimuli to reflect different scenarios of the decision-making process. Pictures (simple clip-art drawings) that conveyed realistic but minimal clues related to the event were used to induce scripts from memory. Some pictures were irrelevant to the event to encourage participants to be selective in their choice of pictures. Every picture was on a separate piece of paper with enough space for written commentary.

A pre-test was done by giving 40 pictures to five individuals (participants of stage 1) for interpretation to determine their reaction, response times and general comments for possible improvement. Following a data driven strategy (clues were provided), they had to select at least 15 pictures to construct a scenario depicting the purchasing of a new washing machine by arranging selected pictures ${ }^{1}$ in sequence adding a written description of what was happening in every scene. Some of the individuals in the scenes were identified by captions (e.g. salesperson, husband) while the rest had to be identified by the participants. No negative comments about the task were raised. Thirty-five pictures were then chosen for the final procedure.

Participants To provide an opportunity for triangulation, all stage 2 participants were invited for participation.

\section{Stage 4: Elicitation of sub-actions and role expec- tations through a data driven, written reconstruc- tion technique}

Script-elicitation procedure Data generated in stages 1 to 3 produced large chunks of activity that were used to identify script norms, key elements and to organize script elements. To overcome a possible neglect of subtle aspects of the decision-making process (Barnes, 1993 based on work by Corsaro \& Heise, 1990) clued recall (Stoltman et al, 1989; Smith \& Houston, 1986) was used in the fourth stage: participants were confronted with a specific scene of the decision-making process based on results of previous stages (in-store activities) which had to be described in detail. They thereafter had to specify in writing, all

\footnotetext{
1: The average number of statements calculated for the previous data-collection stages
} 
the actions that preceded that scene (Schurr, 1986) and concluded with a detailed description of financial decision-making.

Assuming a hierarchical order for script elements, it was expected that although requested and reported out of the natural order, the final result of their reports would correspond with their sequential description in previous elicitation stages. Activities (elements) at the specific level of abstraction were however expected to include more detail due to the nature of the instructions and contributed to confirming the temporal sequence of events.

\section{Participants}

Twenty-five volunteers from the stage 1 sample were recruited for the purpose of triangulation. Because the instructions differed from those in stage 1 and because participants were unaware of the exact objectives of the study, their responses were assumed to be truthful.

\section{Stage 5: Focus group discussions}

Focus groups were used as collective brainstorming sessions to evoke active, spontaneous discussions on certain elements of the purchasing process to conclude the script-elicitation process and for triangulation. Focus group discussions also provided the opportunity to overcome the possible influence of verbalization difficulties that might have hampered reports during previous script-elicitation stages and to confirm the contents and structure of the final script (Morgan, 1988 in Macun \& Posel, 1998; Stoltman et al, 1989).

\section{Data-collection}

A phenomenological approach to focus group discussions was used to uncover everyday knowledge and everyday language (as opposed to scientific knowledge) and to expose generality of ideas (McQuarrie \& Mclntyre, 1988). A response-oriented rather than a question-oriented approach was followed (Robson, 1989:29) to encourage free flow of conversation without excessive control and manipulation of discussions. Participants were encouraged to discuss and debate topics in order to arrive at consensus statements or agreement within the groups. The intention was to reflect on data generated in previous stages, to debate specific issues and to conclude. Conversations were taperecorded for transcription and particular attention was given to concluding remarks and statements. The assistant encouraged participation whenever someone showed reluctance to participate in discussions.

\section{Participants}

Two sessions were held with eleven and seven participants respectively (all from the stage 1 sample) (Payne \& Levy, 1975; Well 1974 in Lautman, 1982). Strangers were grouped together in accordance with their financial status. Nicknames were used to retain anonymity (Macun \& Posel, 1998; Fern, 1983; Cook, 1982). To counteract language difficulties participants were encouraged to participate in language of choice, as all participants understood Afrikaans as well as English.

\section{DATA ANALYSIS AND RESULTS}

Data was analysed immediately after completion of a particular stage in a concerted effort to capture missing or under reported content during the following stage.

\section{Data was analyzed to}

- isolate the relevant script norms and to order the script actions sequentially reflecting the script norms.

- generate the respective script protocols elicited through the various script-elicitation techniques.

- identify main concepts for the purpose of isolating scenes and scene headers.

- evaluate the level of agreement of the script protocols elicited through the various script-elicitation procedures to eventually generate a single theoretical script.

Isolation of script norms and elements and ordering of actions

The data of the first three script-elicitation procedures were used to identify script norms and elements and were eventually integrated. The fourth stage reflected on a basic characteristic of a script, namely that it possesses a set quality (the ability to restructure a script in sequential order when it is entered at any level out of the natural order) while stage 5 focus group discussions served to confirm conclusions and to clarify issues of uncertainty.

The results were as follows:

\section{Stage1: Script-elicitation through a concept driven, written reconstruction technique}

To exclude non-relevant information, responses were edited by the researcher and in so doing the response of one participant was rejected as it reflected a repair scenario which did not contain any useful information. Content analysis of the remaining 57 responses was done. Actions and event statements were coded strictly in accordance with and in the order indicated by the participants. Confirming a report by Yoon and co-workers (1990), individuals revealed during debriefing that they found it easier to reflect on hypothetical events, than to have anticipated a future purchase. The written reports of stage 1 were ideal as a starting point because they produced detailed and relevant descriptions of the event and included information on sensitive financial matters that did not spontaneously surface during stage 2 .

A total of 42 separate actions were identified, ranging from 10 to 21 actions (an average of 15 actions per participant). The fact that only 42 separate actions were identified within the group indicated extensive agreement on the type of actions contained in the event. Content analysis and coding was done by the researcher and independently repeated by a trained

\footnotetext{
2: number of agreements; a: number of disagreements
} 
assistant. Inter-rater reliability was calculated by comparing their interpretations (Touliatos \& Compton, 1988:121, 122):

$[\mathrm{n} /(\mathrm{n}+\mathrm{a})] \times 100=\%$ agreement $^{2}[832+(832+23)]$ $100=97,3 \%$ *

(*Indicative of a high inter-rater reliability for stage 1 ).

A coding form that included all the concepts and actions mentioned by the participants was designed. Actions were transferred in the specific order as identified onto the coding form for statistical analysis. Frequencies were calculated for each action. Because of the low frequency of certain actions (11 actions were mentioned by less than $10 \%$ of the participants) and because some statements were closely related, actions were clustered into related categories, reducing the statements from 42 to 20 generic statements. This is compatible with script theory that postulates that scripts contain generic action statements rather than detailed descriptions of an event (Table 2).

Responses were coded in terms of their positions of the original statements. The mean positions of the generic statements (clusters of the original statements) were then calculated positioning them in sequential order in the script protocol. The script protocol for stage 1 (Table 3 ) indicates the mean position of every generic action as well as the frequency of mention from which main concepts and the strength of actions were determined. The same calculations were done for stages 2 to 4 . Unfortunately space limitation in the publication does not allow for the explicit publication of the results of stages 2 to 4 before the integrated interpretation (Table 6).

The stage 1 protocol provides a clear indication of decision-making schemata (e.g. store visits; price comparisons) and object schemata (e.g. non-personal information sources; retail stores) but does not indicate role schemata satisfactorily (e.g. friends as influencers). Despite clear instructions, participants did not provide enough information on the person- or the role schemata. The missing data on role schemata was calculated at between $n=44$ and $n=56$ for the respective actions. It was decided to actively resolve this shortcoming during the following stages.

To determine the trustworthiness of data, the sample $(n=57)$ was randomly divided into two halves $(n=29$; $n=28$ ) and then compared using the Mann-Whitney rank sum test for two independent groups (Steyn et al, 1994:594). No significant difference in responses and position of mention could be found for any one of the actions mentioned by the two halves of the sample $(p £ 0,05)$ (Table 3$)$ : this indicated trustworthy responses.

\section{Stage 2: Script-elicitation through a concept driven, oral reconstruction technique}

The recorded interviews were transcribed. Content analysis and coding was done in the same way as for stage 1. No new actions to those extracted during stage 1 were added which confirmed the potential of a written technique to elicit detailed descriptions. The same coding schedule as for stage 1 was used. Interrater reliability for the interpretation of data was calculated at $97,4 \%$ (indicative of high inter-rater reliability).

The Mann-Whitney rank sum test for two independent groups was used to determine whether the stage 1 and stage 2 techniques induced the same information from memory. For all but one variable (NEEDS ASSESSMENT) no significant difference in the mean positions of the various script actions in the script protocols for the two studies could be found ( $p £ 0,05$ ). The fact that the mention of NEEDS ASSESSMENT differed for the two procedures may be ascribed to the fact that stage 1 depended upon independent reconstruction of the event while interviews provided the opportunity to interrupt participants and to ask them to elaborate on certain aspects. This probably served as a reminder of certain actions. Participants did however have more time to think during stage 1, which means that the stage 1 data could possibly be a better reflection of the actual sequence of actions. It must further be emphasized that the mean positions of NEEDS ASSESSMENT and actions related to INFORMATION SEARCH are relatively close which means that related actions could be interwoven in a real life situation.

Stage 3: Elicitation of script sub-actions and role expectations, through a data driven discrimination technique

This technique provided more detail than stage 2 in terms of role actions, probably because it served as a

TABLE 2: $\quad$ EXAMPLE OF CLUSTERED ACTION STATEMENTS

\begin{tabular}{|c|c|c|}
\hline Actions mentioned by participants & Initial interpretation & Clustered category \\
\hline $\begin{array}{l}\text {.....decides whether the same brand as the previous one } \\
\text { will be purchased }\end{array}$ & Preference & \multirow[t]{4}{*}{ Needs assessment } \\
\hline Needs assessment & Requirement & \\
\hline $\begin{array}{l}\text { It has to be decided what the household needs first, for } \\
\text { example the capacity needed and where the machine will } \\
\text { be installed }\end{array}$ & Requirement & \\
\hline $\begin{array}{l}\text { Everybody has certain preferences that influences the type } \\
\text { of machine purchased, for example if you are used to a top } \\
\text { loader }\end{array}$ & Preference & \\
\hline
\end{tabular}


TABLE 3: RESULTS: STAGE 1 (CONCEPT DRIVEN, WRITTEN RECONSTRUCTION TECHNIQUE

\begin{tabular}{|c|c|c|c|c|c|}
\hline $\begin{array}{c}\text { Mean } \\
\text { position }\end{array}$ & Variable (action) & $n=57$ & $\%$ & Std dev & P-value* \\
\hline 3.6 & Use of non personal information: written form & 24 & 42 & 2.31869 & 0.4678 \\
\hline 4.1 & Needs assessment & 38 & 67 & 2.50064 & 0.0567 \\
\hline 4.5 & Use of personal information sources: friends, family & 33 & 58 & 3.61715 & 0.1037 \\
\hline 5.5 & Use of personal information: phoning stores & 33 & 58 & 2.41370 & 0.1815 \\
\hline 5.6 & Store visits: to acquire product information & 50 & 89 & 2.62752 & 0.9767 \\
\hline 5.7 & Store visits: to compare products & 35 & 61 & 3.12431 & 0.5036 \\
\hline 5.8 & Store visits: to compare prices & 29 & 51 & 3.28040 & 0.4137 \\
\hline 6.4 & Use of non personal information: product specifications & 20 & 35 & 3.21130 & 0.9388 \\
\hline 6.6 & Financial decisions & 44 & 77 & 3.51655 & 0.8230 \\
\hline 6.7 & Making a shortlist of suitable alternatives & 17 & 30 & 2.99509 & 0.0647 \\
\hline 7.7 & Evaluation of alternatives & 24 & 42 & 3.65263 & 0.5044 \\
\hline 7.8 & Store visits: to compare retailer benefits & 29 & 51 & 2.68903 & 0.9122 \\
\hline 9.9 & Final decision: product & 53 & 93 & 2.96802 & 0.1499 \\
\hline 10.2 & Final decision: store & 29 & 51 & 3.86980 & 0.2482 \\
\hline 10.6 & Store visit: to confirm decision & 8 & 14 & 2.38671 & ** \\
\hline 12.0 & Purchasing action & 57 & 100 & 2.96100 & 0.7973 \\
\hline 13.2 & Delivery & 54 & 95 & 2.92277 & 0.4797 \\
\hline 13.3 & Reconsider decision & 6 & 10 & 2.33809 & ** \\
\hline 13.7 & Study the manual & 7 & 12 & 2.98408 & ** \\
\hline 14.2 & Installation of appliance & 49 & 86 & 2.98792 & 0.4183 \\
\hline ** & $\begin{array}{l}\text { figures indicate the } \\
\text {-Whitney rank sum te }\end{array}$ & 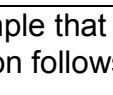 & $\begin{array}{l}\text { ere cc } \\
\text { ater) }\end{array}$ & pared $t$ & $h$ the \\
\hline
\end{tabular}

reminder of experience that did not surface spontaneously during any of the previous stages (Bone \& Ellen, 1990). The discrimination technique addressed a shortcoming of the reconstruction techniques used in stages 1 and 2, which depended on independent reconstruction of the event, which makes it difficult to retrieve information from long-term memory (Bower et al, 1979).

Only 22 of the 25 invited participants arrived for the data-collection session. Because of the intention to compare the results of stages 2 and 3 (the same sample, but different techniques) to determine the trustworthiness of responses, no new participants were included.

Trustworthiness of data was determined using the Mann Whitney rank sum test to compare the data of stages 1 and 3 (two independent groups). For all but one variable (NEEDS ASSESSMENT), there were no significant differences in the responses in terms of the actions mentioned or the ordering of actions in the two script protocols ( $p £ 0,05$ ). The fact that the mention of NEEDS ASSESSMENT differed for the two techniques may be ascribed to the fact that stage 1 depended upon independent reconstruction of the event, while the stage 3 procedure depended upon discrimination. Participants could therefore have been reminded of actions through the pictures provided in stage 3 . With reduced cognitive effort to reconstruct the event from memory, it was possible that the participants could focus more clearly on identifying actions and arranging them in sequential order. The results of stage 3 thus probably reflect the event more accurately. This was confirmed by a comparison be- tween the results of stages 2 and 3 where no significant difference in the results could be found. Once again the mean positions of needs assessment and information search are very close which probably indicates a close interaction of relevant actions during the event.

Responses of stages 2 and 3 (the same sample) were compared using the Wilcoxon rank sum test (Steyn et al, 1994:594). No significant differences in the positions of actions for the two script protocols (excluding subgroups that were too small to merit statistical comparison) ( $p £ 0,05)$ indicate trustworthy data.

\section{Stage 4: Determining the set quality of the script through a data driven, written reconstruction tech- nique}

Three tasks were completed during this stage. Written reports of in-store activities were analysed and coded in the order mentioned by the participants. No new concepts or actions to those indicated in stage 1 came to the fore.

- Participants' descriptions of actions pertaining to the event prior to entering the store were analysed and coded, using the same coding schedule as for stages 1 to 3 .

- Participants' reports of activities relating to financial matters were analysed and coded

Data analysis and coding of responses to the first and second tasks (in-store activities; activities prior to entering the store) were done. Results of the two tasks were integrated in terms of their actual sequential 


\section{TABLE 4: $\quad$ EXAMPLES OF CONCLUDING STATEMENTS OF FOCUS GROUPS**}

\begin{tabular}{|l|l|}
\hline Topic & Responses \\
\hline Role actions & Appliances are very expensive. I do not think that a woman should make such a \\
decision by herself \\
Men consider different characteristics. They must go along to the store so that they \\
can look at more technical things
\end{tabular}

order in the script. Results of the third task (financial decision-making) were analysed and coded and the results were used to elaborate a respondent's mention of financial decision-making in the integrated version of the previous tasks. The stage 4 results only provided data up to the point where consumers left the store. The protocol for stage 4 thus only represented part of the script. Stage 4 results were therefore compared with the stage 1 to 3 versions in terms of face value rather than through statistical analysis.

Needs assessment and information search were, as in the case of stages 1 to 3 , identified as taking place prior to store visits and in the same sequence as mentioned in stage 1 . This occurred during both of the written techniques where participants had enough time to think about their responses. In-store activities coincided with those of previous stages although higher frequencies of actions were reported. This is ascribed to the fact that participants had to focus on specific scenes, which probably induced better reconstruction from long-term memory. In-store activity, due to its apparent significance in all of the stages, became a topic of discussion in the focus group discussions. Table 4 reflects results of stages 1 to 4 to facilitate a comparison of the respective script protocols that were used to generate and motivate the eventual empirical and theoretical script for the acquisition of major household appliances.

\section{Elicitation of role schemata}

The various script-elicitation techniques used were not equally successful in eliciting role schemata. This aspect was for example neglected in stage 1, probably because participants wrote their reports on blank sheets of paper. The design of a report sheet with column indications to remind participants to specify all of the schemata for every action required is recommended for future studies. During stage 2 an effort was made to induce responses by reminding interviewees to specify role behaviour. The projective technique used in stage 3 explicitly expected of participants to identify all individuals in selected pictures and to specify their actions throughout the event. Stage 4 did not produce a full script and from responses it could be concluded that respondents paid more attention to action statements and neglected role actions (the same problem that occurred during the stage 1 written technique). Once again a specially designed report sheet with columns is recommended for future studies.

It would appear that not many persons are involved in a household's decision-making and acquisition of a new appliance. Apart from the involvement of husbands and wives, friends and salespeople seem to make contributions during stages of information seeking while salespeople seem to be influential in-store. Role actions were summarized in table format and

TABLE 5:

\section{PARAMETERS FOR INDICATION OF ACTION STRENGTHS IN THE SCRIPT PROTOCOLS}

\begin{tabular}{|l|l|}
\hline Indicative style of presentation & Frequency (\%) \\
\hline action & $25-39$ \\
\hline action & $40-59$ \\
\hline ACTION & $60-74$ \\
\hline ACTION & $75+$ \\
\hline
\end{tabular}


Scene 1: NEEDS ASSESSMENT

NEEDS ASSESSMENT IN TERMS OF EXPERIENCE, PREFERENCES AND ATTITUDES IS DONE JOINTLY BY HUSBAND AND WIFE OR BY THE WIFE

Scene 2: INFORMATION SEARCH

WRITTEN INFORMATION SOURCES, MAINLY PROMOTIONAL MATERIAL SUCH AS ADVERTISEMENTS ARE USED JOINTLY BY HUSBAND AND WIFE OR BY THE WIFE;

PERSONAL INFORMATION, MAINLY RECOMMENDATIONS OF FRIENDS AND FAMILY, BASED

ON EXPERIENCE IS GENERALLY OBTAINED BY THE WIFE OR JOINTLY;

Telephone enquiries are made to several stores (salespeople), mainly by the wife or jointly

Product specific information such as technical information is gathered mainly by husbands

Scene 3: STORE VISITS

STORES ARE VISITED JOINTLY BY HUSBAND AND WIFE:

TO LOOK AT IN-STORE DISPLAYS AS MAIN SOURCES OF PRODUCT INFORMATION WITH ASSIS-

TANCE OF SALESPEOPLE

TO COMPARE PRODUCTS IN TERMS OF THE HOUSEHOLD'S NEEDS, PERSONAL KNOWLEDGE AND EXPERIENCE

To obtain price information by looking at in-store displays

To investigate product specifications by consulting appliance manuals (mainly by the husband)

Scene 4: FINANCIAL DECISIONS

FINANCIAL DECISIONS, INCLUDING AFFORDABILITY, MEANS OF PAYMENT, WHO IS RESPONSIBLE FOR PAYMENT AS WELL AS FINANCIAL ARRANGEMENTS ARE GENERALLY DELIBERATED JOINTLY BY HUSBAND AND WIFE IN-STORE OR AT HOME

Scene 5: EVALUATION

A shortlist of suitable alternatives is made jointly by husband and wife;

Evaluation of product alternatives is done jointly by husband and wife in-store, or at home;

Stores are compared jointly by both spouses in terms of benefits offered

Scene 6: CHOICE

Final decision of where to purchase the appliance is made jointly by husband and wife

A PRODUCT IS CHOSEN JOINTLY BY HUSBAND AND WIFE

Scene 7: PURCHASING

THE PURCHASE TRANSACTION IS EITHER DONE JOINTLY OR BY THE SPOUSE RESPONSIBLE FOR PAYMENT

Scene 8: DELIVERY

DELIVERY IS GENERALLY DONE/ORGANIZED BY THE RETAILER

Scene 9: INSTALLATION

The appliance manual is generally studied mainly by the wife, but may also be consulted by the husband if he installs the appliance himself

INSTALLATION IS DONE EITHER BY A TECHNICIAN OR THE HUSBAND

FIGURE 2: $\quad$ INTEGRATED EMPIRICAL SCRIPT FOR THE ACQUISITION OF MAJOR HOUSEHOLD APPLIANCES

Making a shortlist was prominently mentioned by between $25-39 \%$ of participants and was therefore included in the script. This action probably did not feature in the stage 3 discrimination task because it is difficult to reflect this action through a drawing.
2 The same argument as the previous one can be used for evaluation of alternatives (indicated by $40-59 \%$ of participants) 
had to be interpreted on face value due to the small samples and disappointingly low responses for some of the actions. The format of the instructions for stage 3 was accepted as more successful in identifying role actions than any of the techniques used. A discussion of role actions was identified as a priority discussion topic for the focus group sessions. The results are reflected in the theoretical script (Figure 2).

Data was transcribed and the contents were analysed. Concluding statements of discussion topics were summarized (Table 4).

\section{ORGANIZATION OF SCRIPT PROTOCOLS}

\section{Identification of strength of actions}

In accordance with previous script studies (Bozinoff, 1982; Bower et al, 1979), the density of grouping of frequencies was used to differentiate and categorize the strength of actions in the various script protocols. Consequently all actions mentioned at frequencies below $25 \%$ were eliminated from the script protocol as being less prominent. All other actions were categorized using the parameters in Table 5. Script protocols were then re-written in the relevant style to make individual actions more easily discernable in terms of their prominence/strength in the empirical script protocols (a practice generally used in script studies).

\section{Empirical script protocols for stages 1 to 4}

Table 6 reflects an integrated version of the results of stages 1 to 4 in terms of strength of actions to enable a comparison of data.

\section{Organization of a single empirical script protocol}

To generate a single script for the event, the level of agreement of the various script protocols had to be determined first. The respective positions of actions in the four script protocols were compared using the Mann Whitney rank sum test for the two halves of stage 1 , to compare stages 1 and 2, and to compare stages 1 and 3 . The Wilcoxon rank sum test was used to compare stages 2 and 3 . The only action that differs significantly in terms of its mean position in the various script protocols is needs assessment in terms of its position in the stage 1 protocol versus the protocols for stages 2 and 3 . It was decided to place needs assessment in the first position based on stage 3 responses as well as consensus statements of focus groups. No significant difference in the mean position of any of the other actions was found (stages 1 to 3 ). The strength of actions was determined by comparing the various script protocols on face value.

Main concepts and elements within a group of related elements were analysed to determine the scene headers. A scene eventually incorporates all related elements (actions mentioned by more than $25 \%$ of participants).
Concepts identified in the initial procedure before a reduction of data from 42 to 20 statements were integrated with basic action statements to enable a more comprehensive expression of some actions I elements (Example: Needs assessment was rewritten as needs assessment in terms of requirements, preferences and experience based knowledge) inclusive of person, object, decision-making and role schemata. The latter was obtained from data generated in stages 2 to 4 .

Figure 2 represents the integrated empirical script for the acquisition of major household appliances as elicited through multiple techniques and taking into consideration the strengths and weaknesses of the various elicitation techniques.

\section{Theoretical script}

Following the rules for the presentation of a script (Weisberg, 1980:55; Bower et al 1979), Table 7 represents the theoretical script for the acquisition of household appliances within a consumer decisionmaking context.

\section{Discussion of the script Scene 1: NEEDS ASSESSMENT}

The first scene represents the deliberation of household needs such as the dimensions and capacity needed by husband and wife. It further entails a consideration of individual factors such as experience with previous appliances and preferences in terms of style, design and brand names. The focus group discussions confirmed that husbands rarely if ever take sole responsibility for so-called white goods because it is still perceived to be a woman's prerogative to specify the need. Focus groups mentioned that financial aspects (affordability) could be part of the discussion of needs in the initial scene although active discussions usually flow from store visits when consumers have had the opportunity to investigate the options.

\section{Scene 2: INFORMATION SEARCH}

Information search prior to store visits is done in terms of the needs identified in scene 1 and is generally limited to non-formal information, mostly promotional in kind such as advertisements found in newspapers and free mail. This is supplemented with personal information from friends and family who act as influencers and share their experiences. Phone calls are also made to different stores for salespeople's recommendations. Information search is generally done jointly or by the wife and include enquiring about brand reputations, performance characteristics, product features, prices and after sales service. Sometimes husbands enquire about technical aspects such as electrical consumption. During focus group discussions it became clear that consumers are ignorant of formal sources of information such as the SABS and Consumer Help Lines supplied by industry via Internet services. Participants agreed that they did not know 
how and where to get information apart from those in newspapers and popular magazines and found those to reflect mainly price, capacity, brand name and guarantee related information. There was consensus that friends' advice is reliable and that salespeople are mostly incompetent in assisting consumers. Their role in the decision-making event could therefore be described as informative (in terms of providing some of the information that could not be found elsewhere).

The mean positions of actions in scenes 1 and 2 are relatively close in all of the script protocols, which indicate that these scenes could in fact be closely interlinked.

\section{Scene 3: STORE VISITS}

Store visits were described as being most important due to the limited availability of product information. Store visits seem to be a joint effort by husband and wife and are made to compare prices, to compare appliances in terms of household needs and to enquire about product specifications. Although consumers consider the role of salespeople in the provision of product information very important, it was agreed that salespeople's persuasive skills cause doubt and that they seldom meet the expectations in terms of competence. At this point retailers and industry were blamed for neglecting this service to consumers.

\section{Scene 4: FINANCIAL DECISIONS}

Financial decision-making was prominently mentioned after the store visits apparently involves husband and wife, including a discussion of affordability (price limitations), method of payment (cash, hire purchase etc), responsibility for payment (husband, wife or jointly) and financial arrangements. Intense discussions of financial decision-making during stage 4 and the focus group discussions, indicated finances to be a prominent determinant during the decisionmaking process due to the amount of money involved and the fact that consumers often have to arrange credit facilities to enable the purchase. Apart from the store visit, deliberation of finances was considered the most important stage of the event. From the arrangement of actions and scenes, it can be deduced that financial discussions are made in terms of needs and information acquired through the store visits and other sources and that the outcome of financial deliberations direct evaluation and choice processes.

\section{Scene 5: EVALUATION}

Identified as a less prominent than any of the other scenes in terms of the strength of actions mentioned, this is a predominantly shared task where husbands and wives compare, discuss and deliberate the product options and store benefits (such as discounts, delivery and installation) either in-store or at home after the store visits. During focus group discussions it became clear that consumers do not really experience an evaluation stage: the process should per- haps rather be described as a search for the suitable appliance that includes evaluation along the way instead of a separate stage of evaluation where options are compared and eliminated (evaluation shopping). The fact that all action statements referring to evaluation were mentioned by fewer than $64 \%$ of participants, confirm this conclusion. During the focus group discussions it was concluded that scenes 3,4 and 5 could take place in-store.

\section{Scene 6: CHOICE}

The final choice of product (mentioned by $75 \%$ and more of the participants) is generally done jointly by husband and wife. Focus groups agreed that men often dominate the decision in terms of the amount of money to be spent and technical aspects. Women's opinions seem to be stronger in terms of the type of appliance preferred. This coincided with what was indicated during needs assessment. This scene may also include "choice of store", i.e. to select the retailer that offers more benefits.

\section{Scene 7: PURCHASE}

The final purchase is generally made jointly or by the spouse who takes responsibility for payment. This confirms a more egalitarian approach to financial decisions in modern households in general.

\section{Scene 8: DELIVERY}

The majority indicated the delivery to be the responsibility or a service provided by the retailer and some even indicated the delivery as a pre-condition of store patronage.

\section{Scene 9: INSTALLATION}

The installation is done by either the consumer (husband) or the retailer, depending on whether the consumer is able to do it. In the clued recall procedure more than half of the participants mentioned "study of the manual" before installation (probably by those who installed the appliances themselves). Those who mentioned it after installation were probably those who had the appliances installed by a technician.

From the empirical script it can be concluded that:

An individual with a less-developed script will probably conclude with the more prominent/stronger actions mentioned by $75 \%$ and more of respondents, namely:

- Needs assessment

- Store visit to acquire information

- Financial decisions

- Final decision product

- Purchasing

- Delivery

- Installation

These are generally referred to as actions that form the common core of the script (Bozinoff, 1982).

Someone with a more developed script will have more actions included in the protocol, namely: 


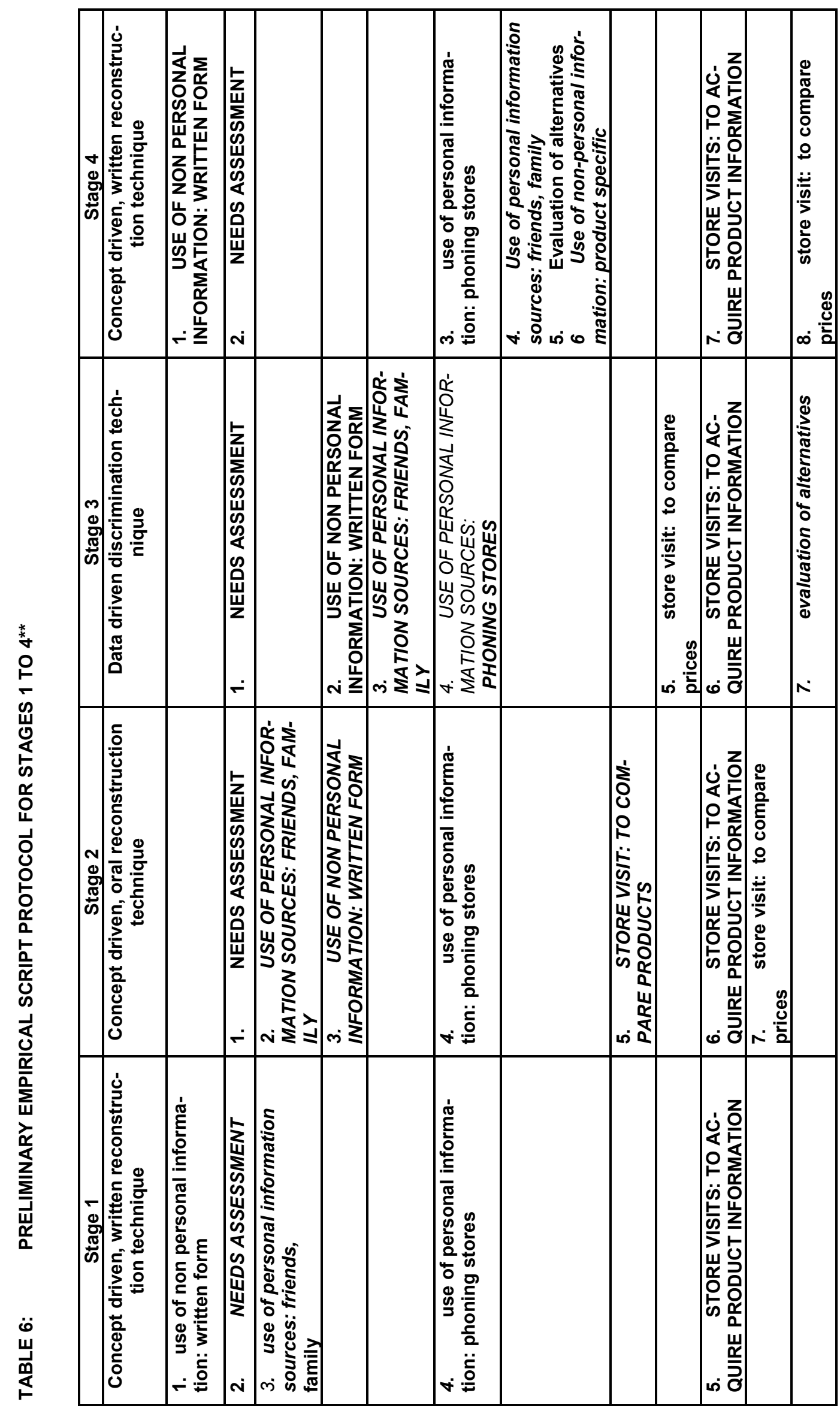




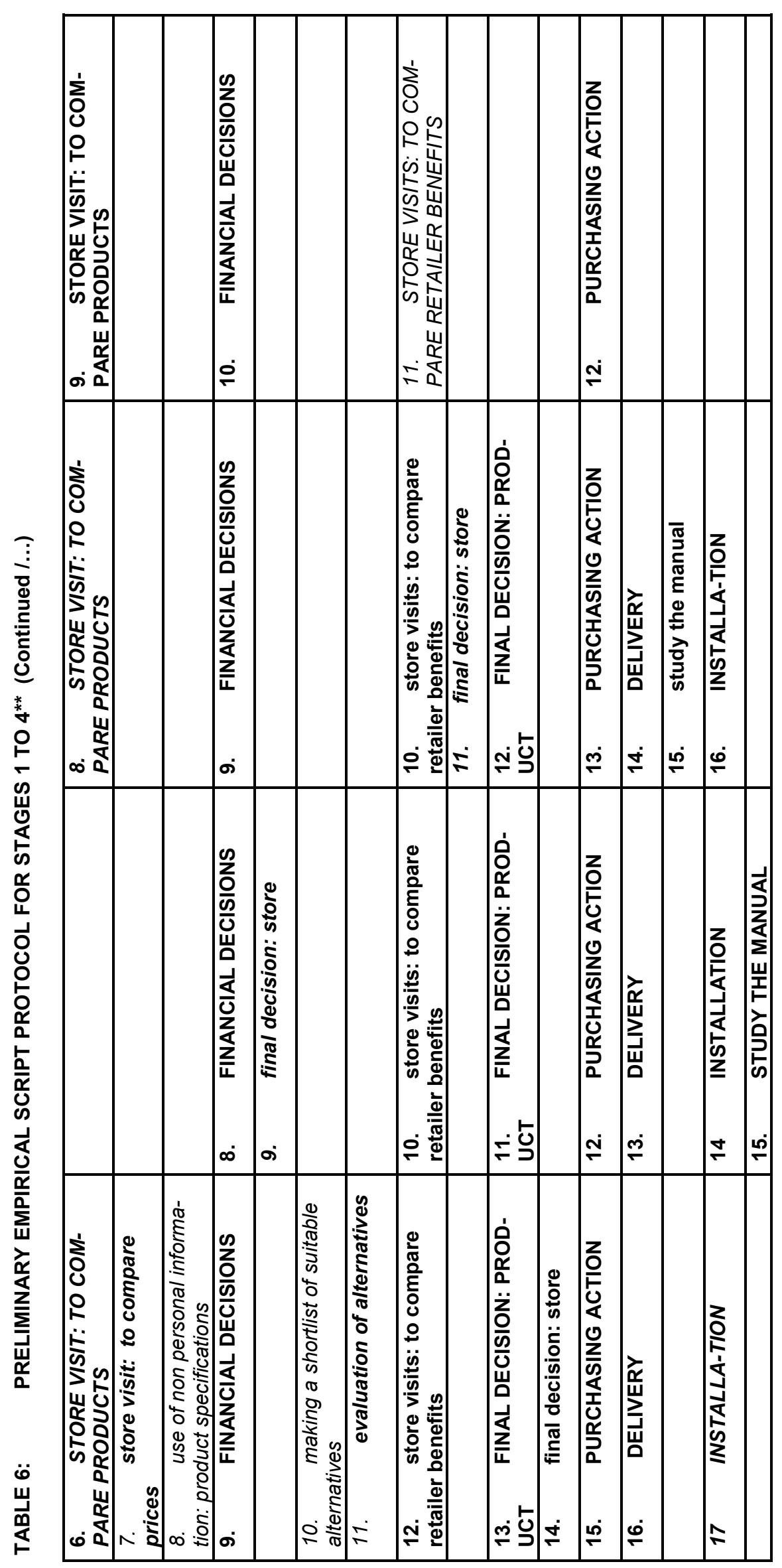


TABLE 7:

THEORETICAL SCRIPT FOR THE ACQUISITION OF MAJOR HOUSEHOLD APPLIANCES

\begin{tabular}{|c|c|c|}
\hline \multicolumn{3}{|l|}{ TITLE: PURCHASING SCF } \\
\hline \multicolumn{2}{|c|}{$\begin{array}{l}\text { Person schemata: } \\
\text { Consumer (male, female); Friends; Family; Salesper- } \\
\text { son; Cashier }\end{array}$} & $\begin{array}{l}\text { Roles: } \\
\text { Consumer; Sales person; Advisor; Technician; } \\
\text { Delivery man; }\end{array}$ \\
\hline \multicolumn{2}{|c|}{$\begin{array}{l}\text { Object schemata: } \\
\text { Advertisements; Appliances; Stores; Store display; } \\
\text { Instruction manuals; Money; Credit cards; Sales docu- } \\
\text { ments; Telephone; Guarantees }\end{array}$} & \\
\hline \multicolumn{2}{|c|}{$\begin{array}{l}\text { Entry condition: } \\
\text { Household needs an appliance } \\
\text { Consumer has money }\end{array}$} & $\begin{array}{l}\text { Outcomes: } \\
\text { Consumer owns new appliance } \\
\text { Consumer has less money } \\
\text { Retailer (sales person) has made a sale }\end{array}$ \\
\hline SCENE & \multicolumn{2}{|c|}{ SCENE ELEMENTS IN TERMS OF STRENGTH OF ACTION } \\
\hline $\begin{array}{l}\text { Scene } 1 \\
\text { NEEDS ASSESSMENT }\end{array}$ & \multicolumn{2}{|c|}{$\begin{array}{l}\text { Needs assessment in terms of experience, preferences and attitudes is done } \\
\text { jointly by husband and wife or by the wife }\end{array}$} \\
\hline $\begin{array}{l}\text { Scene } 2 \\
\text { INFORMATION SEARCH }\end{array}$ & \multicolumn{2}{|c|}{$\begin{array}{l}\text { Written information sources, mainly promotional material such as advertisements } \\
\text { are used jointly by husband and wife or by the wife; } \\
\text { Personal information, mainly recommendations of friends and family, based on } \\
\text { experience is generally obtained by the wife or jointly; } \\
\text { Telephone enquiries are made to several stores (salespeople), mainly by the wife } \\
\text { or jointly } \\
\text { Product specific information such as technical information is gathered mainly by } \\
\text { husbands }\end{array}$} \\
\hline Scene 3: STORE VISIT & \multicolumn{2}{|c|}{$\begin{array}{l}\text { Stores are visited jointly by husband and wife: } \\
\text { To look at in-store displays as main sources of product information with assis- } \\
\text { tance of salespeople } \\
\text { To compare products in terms of the household's needs, personal knowledge and } \\
\text { experience } \\
\text { To obtain price information by looking at in-store displays } \\
\text { To investigate product specifications by consulting appliance manuals (mainly by } \\
\text { the husband) }\end{array}$} \\
\hline $\begin{array}{l}\text { Scene } 4 \\
\text { FINANCIAL }\end{array}$ & \multicolumn{2}{|c|}{$\begin{array}{l}\text { Financial decisions, including affordability, means of payment, who is responsible } \\
\text { for payment as well as financial arrangements are generally deliberated jointly by } \\
\text { husband and wife in-store or at home }\end{array}$} \\
\hline Scene 5: EVALUATION & \multicolumn{2}{|c|}{$\begin{array}{l}\text { A shortlist of suitable alternatives is made jointly by husband and wife, } \\
\text { Evaluation of product alternatives is done jointly by husband and wife in-store or } \\
\text { at home; } \\
\text { Stores are compared jointly by both spouses in terms of benefits offered }\end{array}$} \\
\hline Scene 6: CHOICE & \multicolumn{2}{|c|}{$\begin{array}{l}\text { Final decision of where to purchase the appliance is made jointly by husband and } \\
\text { wife } \\
\text { A product is chosen jointly by husband and wife }\end{array}$} \\
\hline Scene 7: PURCHASE & \multicolumn{2}{|c|}{$\begin{array}{l}\text { The purchase transaction is either handled jointly or by the spouse responsible } \\
\text { for payment }\end{array}$} \\
\hline Scene 8: DELIVERY & \multicolumn{2}{|c|}{ Delivery is generally done/organized by the retailer } \\
\hline Scene 9: INSTALLATION & \multicolumn{2}{|c|}{$\begin{array}{l}\text { The appliance manual is generally studied mainly by the wife, but may also be } \\
\text { consulted by the husband if he installs the appliance himself } \\
\text { Installation is done either by a technician or the husband }\end{array}$} \\
\hline
\end{tabular}

- Use of non-formal written information sources (advertisements, etc.)

- Use of non-formal personal information sources (asking friends, phoning stores)

- Comparison of products.

More experienced consumers will include even more actions, namely:

- visits to different stores to compare retailer benefits;

- compilation of a shortlist of alternatives;

- use of formal information namely product specifications.

\section{CONCLUSION}

Any new script that is elicited and generated has to be evaluated and discussed in terms of the basic properties and structural characteristics of a script to determine whether the script can be accepted and acknowledged for further use within the theoretical framework of a discipline. The script generated for the acquisition of major household appliances was thus evaluated. 


\section{Properties of the script}

In terms of the basic properties of a script (Bower et al, 1979 in Bozinoff \& Roth, 1983 as discussed in Erasmus et al, 2002a), the following can be concluded:

Action statements were elicited in a very uniform and logical way in all four stages of the scriptelicitation procedure despite the difference in techniques used to reconstruct the particular purchasing event. The level of agreement calculated for the various scripts confirm a remarkable resemblance. For all but one action (needs assessment), there was no significant difference in the order of the action statements (elements) of the four groups of data (two halves of stage 1; stage 2; stage 3 ) when they were compared with one another $(p \leq 0.05)$. The logical order of the action statements in the final script should also be noted. Keeping in mind that participants were allowed to react spontaneously with minimum guiding as to what were to be included in their reports, the end results strongly indicate the existence of script knowledge in memory. Despite differences in the various elicitation techniques in terms of approach and application, there was little fluctuation in content when the results of the various stages were compared. In fact, after implementation of the written elicitation technique in stage 1 , no additional action statements were added as a result of the other techniques that were used. The number of action statements identified during the first three stages shows minor difference $(17,15$ and 16 statements respectively) (Table 6).

Script norms (person, object, decision-making schemata) for the specific event were easily identifiable except for the elicitation of role schemata that posed some practical problems. This can be ascribed to the unstructured way of script-elicitation, which probably resulted in participants' forgetting to specify roles during their description of actions of the event. Participants had no problem in identifying role actions during stages 3 and 5 when they were very specifically reminded to elaborate. The same script norms were evoked through all of the first three script-elicitation techniques and a specific order of actions/scenes was thereafter determined. Except for one action, needs assessment, that was indicated a second action in stage 1 , there were no significant differences in the positions of activities in the various script protocols ( $p$ $\leq 0,05$ ) found for the various elicitation procedures.

Action sequences were spontaneously grouped into scenes/elements (Table 6) where the more prominent/stronger actions could be used to specify scene headers. Weaker activities were in fact activities that depended upon the stronger actions for occurring (e.g. make a shortlist of alternatives as part of the scene evaluation of alternatives). Scenes in the final script form a logical order considering the five basic steps of consumer decision-making (Schiffman \& Kanuk, 2000:444). Main concepts were easily discernible and when analysed on their own can be as regarded actions that always take place (Den Uyl \& Van Oostendorp, 1980).

Script elements were organized in a common order: no significant difference in the position of activities, thus the order in the script protocols in the first three script protocols $(p \leq 0,05)$ was found. A final integrated script protocol could be reached without major effort. This aspect was put to test in the fourth scriptelicitation procedure, and once again, participants had no problem to reconstruct elements of the event (either before or after the specified scene) in the same order as before.

From the data generated, it can be concluded that although not conscious of scripted activities - participants succeeded in reconstructing the acquisition process of household appliances in a very uniform, ordered way, when encouraged to do so. Some elicitation techniques did evoke more detail (in written procedures participants often included detail such as poor assistance of salespeople, delivery problems and detail surrounding financial arrangements) (Bozinoff \& Roth, 1983). Despite the fact that a few participants acted hesitantly when they received their instructions when introduced to script-elicitation sessions and indicated that they needed time to think before they responded, they were very co-operative, produced valuable responses and were very willing to take part in follow-up procedures.

\section{Structural characteristics of a script}

When judging the structural characteristics of the script (Bower et al, 1979 in Bozinoff \& Roth, 1983 as discussed in Erasmus et al, 2002a), the following can be concluded:

Only generic actions are contained in the script: this can be concluded from the limited number of scenes and activities in the final script as well as the fact that the activities as formulated and indicated are very basic in nature.

The script possesses a set quality: when confronted with a single scene in the fourth script-elicitation stage, participants experienced no problem to complete the script even though the level of abstraction they were confronted with, was somewhere near the middle of the script.

A strong temporal sequence of script activities was identified through the correlation of the sequence of actions/scenes in the different script-elicitation procedures. This was confirmed in the focus group discussions: participants found it unthinkable to go to the store without deliberating household needs and found it absolutely necessary to organize finances before making a final decision regarding the product.

A hierarchical structure was evident (Smith \& Houston, 1986). Elements of the script protocols were almost spontaneously grouped into scenes in a very 
logical order that showed some resemblance to the basic flow of stages of a consumer decision-making process. No problem was experienced in identifying scene headers or to group and arrange scene actions of variable strength that interconnected as logic elements of a specific scene.

Based on the level of agreement of the responses elicited during the various stages, the script-elicitation procedure can be regarded successful in eliciting a script for the specific event. With reference to the script norms, it can be concluded that the relevant person, object and decision-making schemata were elicited and indicated without hesitation. More attention should however be given to the elicitation of role schemata. Script elements were eventually arranged in a logical sequential order. Because of the level of agreement between the various script protocols (stages 1 to 4 ) the generation of the final script was based on logical conclusions. This qualifies the script for the acquisition of major household appliances as a so-called strong script (Bozinoff \& Roth, 1983) where actions are clearly specified and arranged in the minds of experienced consumers.

The attempt to elicit and generate a purchasing script, more specifically a script for obtaining major household appliances within the consumer decision-making context, proved successful. The selection, combination and order of performing the various scriptelicitation techniques proved to be successful in eliciting the relevant schemata and in generating a script that adheres to the basic properties and structural characteristics of a script. More attention should however be given to the elicitation of role schemata during stages 1 and 4 by providing a specially designed sheet instead of blank paper. This particular study fortunately - as a result of the selection and specific ordering of script-elicitation techniques - provided the opportunity to remedy problems during subsequent stages. The stage 3 discrimination technique and the consequent focus group discussions were used to clarify uncertainties regarding role schemata.

Although - in retrospect - it was determined that all the relevant script actions were already identified in stage 1 , the successive stages were necessary for triangulation purposes and to elicit role schemata, which did not surface clearly during stages 1 and 2 . The specific order of script-elicitation techniques is recommended for future research. Leigh and $\mathrm{Re}-$ thans' (1983) observation that the process will eventually determine the length of the script is hereby confirmed: the written technique succeeded in eliciting all the relevant actions while consequent techniques were useful to elaborate on specific aspects and to design visual stimuli for discrimination purposes. Although the stage 4-elicitation procedure did not change or contribute additional information to the information that had already been generated through the preceding procedures, it did confirm the recall of action sequences from any entry level in the script to confirm the structural characteristics of a script. The focus group discussions were vibrant and supported the information collected during the previous stages. It was found to be a satisfactory technique to discuss and debate role behaviour.

\section{RECOMMENDATIONS}

It is recommended that the format and content of the script be considered as a model-like representation of the purchasing event and may be used to anticipate or reflect consumer decision-making behaviour for the acquisition of major household appliances. The fact that a script represents the portrayal of the event from the view of the consumer, provides the opportunity to:

- identify areas of concern (limited use of objective information due to unavailability, ignorance; instore facilities) that need to be addressed to improve the process as well as the outcome of decisions;

- properly structure and make available product information in the form and format that address consumers' - both men and women - needs;

- sensitise retail towards consumers' needs so that in-store activities could be used as a more satisfactory purchasing experience;

- direct promotional effort sensibly and effectively to educate, inform and limit uncertainty and doubt;

- design educational programmes that would in the long and short-term result in more responsible consumer decision-making behaviour.

\section{REFERENCE LIST}

ABELSON, RP. 1981. Psychological status of the script concept. American Psychologist 36(7):715729.

ALDERSHOFF, DE. 1985. Final food consumption level based on expenditure and household production. Advances in Consumer Research XII:209-214. Fifteenth Annual Conference. [sl]. Association for Consumer Research.

BARNES, JH. 1993. Ethno: A methodology to studying process of information. Advances in Consumer Research XX:63-69. Twenty Third Annual Conference. [sl]. Association for Consumer Research.

BONE, PF \& ELLEN, PS. 1990. The effect of imagery processing and imagery content on behavioral intentions. Advances in Consumer Research XVII:449454. Twentieth Annual Conference. [sl]. Association for Consumer Research.

BOWER, GH, BLACK, JB \& TURNER, TJ. 1979. Scripts in memory for text. Cognitive Psychology (11):177-220.

BOZINOFF, L. 1982. A script theoretic approach to information processing: an energy conservation application. Advances in Consumer Research IX:481-486. Twelfth Annual Conference. [sI]. Association for 
Consumer Research.

BOZINOFF, L \& ROTH, VJ. 1983. Recognition memory for script activities: an energy conservation application. Advances in Consumer Research X:655660. Thirteenth Annual Conference. San Francisco. Association for Consumer Research.

BROWN, TJ. 1992. Schemata in consumer research: a connectionist approach. Advances in Consumer Research XIX:787-794. Twenty Second Annual Conference. [sl]. Association for Consumer Research.

BUSS, WC \& SCHANINGER, CM. 1983. The influence of sex roles in family decision-making. Advances in Consumer Research X:439-444. Thirteenth Annual Conference. San Francisco. Association for Consumer Research.

COOK, WA. 1982. Turning focus groups inside out . Advances in Consumer Research IX:62-65. Twelfth Annual Conference. New Orleans. Association for Consumer Research.

CORSINI, RJ. 1994. Encyclopedia of Psychology. Vol. 2. New York. John Wiley.

COX, A, GRANBOIS, DG \& SUMMERS, J. 1983. Planning, search, certainty and satisfaction among durables buyers: a longitudinal study. Advances in Consumer Research X:394-399. Thirteenth Annual Conference. San Francisco. Association for Consumer Research.

DEN UYL, M \& VAN OOSTENDORP, H. 1980. The use of scripts in text comprehension. Poetics (9):275294.

DENZIN, NK \& LINCOLN, YS. 2000. Handbook of Qualitative Research. 2 nd ed. London. Sage.

DONOGHUE, S. 2000. Projective techniques in consumer research. Journal of Family Ecology and Consumer sciences 28:47-53. http://www.up.ac.za/academic/acadogs/saafecs/vol28 /donoghue.html

DU PLESSIS, PJ \& ROUSSEAU, GG. 1999. Buyer Behaviour. A Multi Cultural Approach. Halfway House. International Thopson Sigma.

ERASMUS, AC, BOSHOFF, E \& ROUSSEAU, GG. 2001. Consumer decision-making models within the discipline of consumer science: a critical approach. Journal of Family Ecology and Consumer Sciences 29:82-90. http://www.up.ac.za/academic/acadogs/saafecs/vol29/erasmus.html

ERASMUS, AC, BOSHOFF, E \& ROUSSEAU, GG. 2002a. Script theory in consumer behaviour research. Journal of Family Ecology and Consumer Sciences 30:1-9.http://www.up.ac.za/academiclacadogs/saafecs/vol30/erasmus.html

ERASMUS, AC, BOSHOFF, E \& ROUSSEAU, GG. 2002b. A procedure for the elicitation of a script for the acquisition of household appliances within the consumer decision-making context. Journal of Family Ecology and Consumer Sciences 30:21-30.

FERN, EF. 1983. Focus groups: a review of some contradictory evidence, implications and suggestions for future research. Advances in Consumer Research XX:121-129. Thirteenth Annual Conference. [sl]. Association for Consumer Research.

GARDNER, MP \& RAJ, SP. 1983. Responses to commercials in laboratory versus natural settings: a conceptual framework. Advances in Consumer Research X:142-146. Thirteenth Annual Conference. San Francisco. Association for Consumer Research. HOY, MG. 1991. The emergence of script related knowledge. Marketing theory and applications (2):387-394. American Marketing Association Winter's Conference.

HUBERMAN, AM \& MILES, MB. 1994. Data management and analysis methods. In DENZIN, NK \& LINCOLN, Y. The Handbook of Qualitative Research. Thousand Oaks. Sage.

HUDSON, LA \& MURRAY, JB. 1986. Methodological limitations of the hedonic consumption paradigm and possible alternative: a subjectivist approach. Advances in Consumer Research XIII:343-348. Sixteenth Annual Conference. [sl]. Association for Consumer Research.

JOHN, G \& WHITNEY, JC. 1982. An empirical investigation of the serial structure of scripts. An Assessment of Marketing Thought and Practice. American Marketing Association. Chicago.

LA TOUR, SA. 1983. Reliability and validity in consumer research: where do we go from here? Advances in Consumer Research XIII:696-698. Sixteenth Annual Conference. [sl]. Association for Consumer Research.

LAI, AW. 1994. Consumption schemata: their effects on decision-making. Advances in Consumer Research XXI:489-494. Twenty third Annual Conference. [sl]. Association for Consumer Research.

LAUTMAN, MR. 1982. Focus groups: theory and method. Advances in Consumer Research XIX:5255. Twelfth Annual Conference. [sl]. Association for Consumer Research

LEIGH, TW \& RETHANS, AJ. 1983. Experiences with script-elicitation within consumer decision making contexts. Advances in Consumer Research X:667678. Thirteenth Annual Conference. San Francisco. Association for Consumer Research.

MACUN, I \& POSEL, D. 1998. Focus groups: a South African experience and a methodological reflection. African Sociological Review 2(1):114-135. MANO, H \& DAVIS, SM. 1990. The effects of familiarity on cognitive maps. Advances in Consumer Research XVII:275-282. Twentieth Annual Conference. New Orleans. Association for Consumer Research. McQUARRIE, EF \& McINTYRE, SH. 1988. Conceptual underpinnings for the use of group interviews in consumer research. Advances in Consumer Research XV:580-586. Eighteenth Annual Conference. New Orleans. Association for Consumer Research. MENON, G \& JOHAR, G. 1993. "Yes I remember it well...." The role of autobiographical memory in consumer information processing. Advances in Consumer Research XX:108. Twenty Third Annual Conference. [sl]. Association for Consumer Research. MOUTON, J. 1996. Understanding Social Research. Pretoria. Van Schaick.

ROBSON, S. 1989. Group discussions. In ROBSON, S \& FOSTER, A. Qualitative Research in Action. [sl]. Edward Arnold.

SCHURR, PH. 1986. Four script studies: What we have learnt. Advances in Consumer Research XIII:498-508. Sixteenth Annual Conference. [sl]. 
Association for Consumer Research.

SMITH, RA \& HOUSTON, MJ. 1986. Measuring script development: an evaluation of alternative approaches. Advances in Consumer Research XIII:504508. Sixteenth Annual Conference, [sl]. Association for Consumer Research.

SPECK, PS, SCHUMANN, DW \& THOMPSON, CT. 1988. Celebrity endorsements - scripts, schema and roles. Advances in Consumer Research XV:69-75. Eighteenth Annual Conference. [sl]. Association for Consumer Research.

STEYN, AGW, SMIT, CF, DU TOIT, SHC \& STRASHEIM, C. 1994. Modern Statistics in Practice. Pretoria. Van Schaick Academic.

STOLTMAN, JJ, TAPP, SR \& LAPIDUS, RS. 1989. An examination of shopping scripts. Advances in Consumer Research XVI:384-391. Nineteenth Annual Conference. [sl]. Association for Consumer Research.

TAYLOR, SA, CRONIN, JJ jr \& HANSEN, RS. 1991. Schema and script theory in channels research. Mar- keting Theory and Applications(2):15-24. American Marketing Association Winter's Conference. [sl]. TOULIATOS, J \& COMPTON, NH. 1988. Research Methods in Human Ecology. lowa. Iowa State University Press.

VENKATESH, A. 1985. A conceptualization of the household/technology interaction. Advances in Consumer Research XII:189-194. Fifteenth Annual Conference. [sl]. Association for Consumer Research. WEISBERG, RW. 1980. Memory, Thought, Behavior. Oxford University Press. Oxford.

WHITNEY, JC \& JOHN, G. 1983. An experimental investigation of intrusion errors in memory for script narratives. Advances in Consumer Research X:661666. Thirteenth Annual Conference. San Francisco. Association for Consumer Research.

YOON, C, MEYERS-LEVY, JM \& TYBOUT, A. 1990. Exploring temporal perspective framing effects. $A d$ vances in Consumer Research XVII:533. Twentieth Annual Conference. New Orleans. Association for Consumer Research. 